\title{
Interdependencias y rupturas de la participación y planeación del territorio en Colombia, a partir de $1991^{1}$
}

\author{
Interdependencies and ruptures of the participation and planning of the \\ territory in Colombia, from 1991
}

\begin{abstract}
Interdependências e rupturas de participação e planeamento do território, na Colômbia, a partir de 1991
\end{abstract}

\author{
Gleidy Alexandra Urrego Estrada ${ }^{2}$
}

Recibido: 03.11.2016 - Arbitrado: 19.01.2017 - Aprobado: 28.02.2017

\begin{abstract}
Resumen
El artículo tiene como objetivo identificar el proceso de planeación territorial y su implicación político-social en los municipios colombianos, a través de relación entre la planeación y la participación que evoca debatir la construcción del territorio como asunto de configuración de lo público. La ruta metodológica es de enfoque cualitativo, nivel descriptivo y método bibligrafico. Resultados: la participación en clave de planificación territorial en los municipios colombianos abarca un compromiso social de deliberación política sobre la visión del territorio, que comprende su uso, cambio y su carga simbólica (el territorio significado). Discusión: Si bien, la planeación del territorio evidencia una democratización de la intervención de la ciudadanía en asuntos locales, también, puede ser causa de parálisis en las decisiones en el poder político directo del ámbito local. Conclusiones: la participación en clave de planificación territorial en el municipio colombiano abarca características como: inclusión (apertura a otras voces y otros sectores), incidencia (contribuir a acciones colectivas), deliberación (debates, consensos y disensos), apertura al diálogo de saberes y aprendizaje colectivo que permitan disminuir asimetrías en la producción y circulación de información y concentración de poderes territoriales.
\end{abstract}

Palabras clave: participación, planificación, territorio, local

\begin{abstract}
The article aims to identify the process of territorial planning and its political and social involvement in Colombian municipalities, through a relationship between planning and participation that evokes discussing the construction of the territory as a matter of configuration of the public. The methodological route is qualitative descriptive, when approaching the
\end{abstract}

\footnotetext{
${ }^{1}$ Este artículo es producto del proyecto de investigación "Análisis de las estructuras administrativas existentes en los Municipios que conforman la subregión del Magdalena medio del Departamento de Antioquia en el periodo 2012-2015, en cuanto a la gestión, lo financiero y económico, frente al Ordenamiento Territorial y el Nuevo Régimen Municipal desde una perspectiva económica" del grupo de Investigación Observatorio Público. Institución Universitaria Tecnológico de Antioquia (TdeA).

${ }^{2}$ Magíster en Hábitat, Universidad Nacional de Colombia. Administradora Pública, Escuela de Administración Pública ESAP. Institución Universitaria Tecnológico de Antioquia. Medellín, Colombia, gleidy.urrego@gmail.com

Citación del artículo: Urrego, G. (2017). Interdependencias y rupturas de la participación y planeación del territorio en Colombia, a partir de 1991. Revista Katharsis, N 23, enero-julio 2017, pp.236-259, Disponible en http://revistas.iue.edu.co/index.php/katharsis
} 
participation in key of territorial planning at local scale. Results: participation in the territorial planning key in the Colombian municipalities encompasses a social commitment of political deliberation on the vision of the territory, which includes its use, change and its symbolic load (meaning territory). Discussion: Although the planning of the territory shows a democratization of the intervention of the citizenship in local affairs, also, it can be cause of paralysis in the decisions in the direct political power of the local scope. Conclusions: participation in the territorial planning code in the Colombian municipality includes aspects such as inclusion (openness to other voices and other sectors), incidence (contributing to collective actions), deliberation (debates, consensus and dissension), openness to dialogue Knowledge and collective learning that allow to diminish asymmetries in the production and circulation of information and concentration of territorial powers.

Keywords: Participation, planning, territory, local

\section{Resumo}

$\mathrm{O}$ artigo tem como objetivo identificar o processo de planejamento territorial e sua participação política e social nos municípios colombianos, através da relação entre planejamento e participação que evoca discutir a construção do território como uma questão de ajustes públicos. O percurso metodológico é descritiva qualitativa, ao abordar a participação fundamental no ordenamento do território a nível local. Resultado: a participação no planeamento regional chave no compromisso social municípios colombianos engloba um debate político sobre a visão do território, o que inclui seu uso, mudança e simbólico (ou seja, o território). Discussão: Ao planear a democratização provas território de intervenção dos cidadãos em assuntos locais, também pode causar paralisia nas decisões sobre o poder político directo a nível local. Conclusões: a participação no planeamento regional chave no município colombiano inclui características como: inclusão (aberto a outras vozes e outros sectores), incidência (contribuir para acções colectivas), deliberação (debates, confluências e dissonâncias), abertura ao diálogo conhecimento e aprendizagem coletiva a fim de diminuir as assimetrias na produção e circulação de informações ea concentração territorial dos poderes.

Palavras chaves: participação, o planejamento, território, local

\section{Introducción}

Con la constitución política de 1991 en Colombia la planeación territorial ${ }^{3}$ y la participación aparecen en la escena del país como la articulación de toda organización social, civil, política, institucional; a su vez, en procesos de racionalidad y gobernabilidad que implican legitimidad en todo el proceder administrativo del municipio. Además, quiso la constituyente

\footnotetext{
${ }^{3}$ La planeación y el ordenamiento territorial, de acuerdo con el Decreto 879 de 1998: Artículo $2^{\circ}$.- Ordenamiento del territorio. De conformidad con los artículos 5 y 6 de la Ley 388 de 1997, el ordenamiento del territorio municipal o distrital comprende un conjunto de acciones político-administrativas y de planeación física concertadas y coherentes, emprendidas por los municipios o distritos y áreas metropolitanas para disponer de instrumentos eficaces de orientación del desarrollo del territorio bajo su jurisdicción y de regulación de la utilización, ocupación y transformación de su espacio físico. El ordenamiento territorial debe ser acorde con las estrategias de desarrollo económico del municipio y distrito y armónico con el mismo ambiente y sus tradiciones históricas y culturales.

Citación del artículo: Urrego, G. (2017). Interdependencias y rupturas de la participación y planeación del territorio en Colombia, a partir de 1991. Revista Katharsis, N 23, enero-julio 2017, pp.236-259, Disponible en http://revistas.iue.edu.co/index.php/katharsis
} 
plantear un reto, a partir de la oferta pública dada en la descentralización que profundiza las responsabilidades sociales en la construcción del desarrollo local. Sin embargo, argumenta Chaparro (2007:24):

(...) aun no es posible cumplir con las exigencias de las entidades nacionales y territoriales para una efectiva formulación y ejecución de sus planes de desarrollo y de ordenamiento territorial. Situación que se origina en la insuficiente asignación de recursos presupuestales, y en la falta de coordinación interinstitucional e intersectorial, así como en la insuficiente capacidad instalada de las entidades productoras de información a nivel nacional para satisfacer las exigencias del mercado.

En esa media, la planeación territorial y la participación como reto y mandato constitucional manifiesto en el artículo 311, al establecer al municipio como célula central del Estado colombiano, quien promueve el desarrollo de su territorio, los servicios públicos y la participación comunitaria; así mismo, la planeación y la participación se establecen, complementan y difunden en la organización institucional, a través del componente político, administrativo y territorial. Este último componente se fortalece en la Ley 388 de 1997, que establece la participación democrática como parte de la acción urbanística, y precisamente "las administraciones municipales, distritales y metropolitanas deberán fomentar la concertación entre los intereses sociales, económicos y urbanísticos, mediante la participación de los pobladores y sus organizaciones" (artículo $4^{\circ}$, párrafo 1.). Argumenta Trujillo que el municipio colombiano puede desarrollar una estrategia múltiple (2007:201):

Tres son, por lo menos, las direcciones de aquella estrategia: la eficiencia de la administración pública, objetivo que se inscribe en el marco general de las reglas del mercado; el desarrollo económico y social, objetivo en el que aparecen coincidencias entre los voceros del establecimiento y sus más radicales opositores; la transformación institucional, que tiene un evidente contenido democrático y convoca a los partidos más decididos de la tendencia social del derecho y del Estado.

Precisamente la concertación de estos intereses es armonizada en los principios que establece el artículo $2^{\circ}$ de dicha ley, y ratifica la Ley 1454 de 2011: 1. La función social y ecológica de la propiedad; 2. La prevalencia del interés general sobre el particular y; 3 . La distribución equitativa de las cargas y los beneficios. A su vez, el mismo artículo $4^{\circ}$ determina la participación ciudadana a través de canales como: "derecho de petición, la celebración de audiencias públicas, el ejercicio de la acción de cumplimiento en los procesos de otorgamiento, modificación, suspensión o revocatoria de las licencias urbanísticas, en los términos establecidos en la Ley 388 y sus reglamentos". Explica Ornez \& Chacón (2009:8):

Citación del artículo: Urrego, G. (2017). Interdependencias y rupturas de la participación y planeación del territorio en Colombia, a partir de 1991. Revista Katharsis, N 23, enero-julio 2017, pp.236-259, Disponible en http://revistas.iue.edu.co/index.php/katharsis 
En el contexto de la planificación y la gestión urbana, ya existen suficientes evidencias que muestran que la capacidad de respuesta ante los problemas de las ciudades o centros poblados se encuentra desfasada con respecto a la necesidad e importancia de la resolución de los mismos. Cualquier metodología de planificación urbana con inclusión de la variable riesgo ambiental debe apostar por una gestión inteligente de los recursos naturales y de la resiliencia económica y social a nivel local, divisando la reducción del riesgo a partir de una política de desarrollo urbano clara, integral, construida por todos los actores, y dentro de un contexto territorial más amplio.

Ahora bien, la participación ciudadana en las acciones territoriales que se interesa resaltar es la intervención propositiva, constante e incidente por parte de la población en la formulación, discusión y ejecución del plan básico de ordenamiento territorial en los municipios colombianos. En tanto, la planeación territorial es proceso para el desarrollo local que se sirve del conocimiento del contexto y de exigencias contextuales, esto es, de lo que afuera de la administración pública local sucede con demandas económicas, sociales, políticas y culturales de lo nacional y local (centro) que determinan los modos de intervención político-administrativa del municipio colombiano. Complementa Gallicchio (2010:22):

Sin embargo, no es suficiente la voluntad de territorializar las políticas desde el centro, ese es un paso sustantivo porque implica voluntad política y recursos, pero la articulación solo puede ser generada desde el territorio. Para ello es necesario, como se ha señalado, considerar simultáneamente acciones en torno a la gobernanza multinivel, a la construcción de capital social y al desarrollo económico local.

De igual manera, en el municipio, la realidad de la planificación del territorio es evidente y, ante todo, la injerencia de la población en la configuración y apropiación del territorio es esencial para su transformación. En tanto, la finalidad del artículo es identificar el proceso de planeación territorial y su implicación político-social en los municipios colombianos, a través de relación entre la planeación y la participación que evoca debatir la construcción del territorio como asunto de configuración de lo público. En la primera parte, se establece la relación entre planeación territorial y participación. En la segunda, el territorio como vínculo entre la planeación y la participación desde el Plan básico de ordenamiento territorial en los municipios colombianos. En la tercera parte, se aborda los horizontes de articulación entre planeación territorial, participación y territorio. Finalmente se concluye con una propuesta hacia una planeación territorial participativa para el municipio colombiano.

\section{Método}

La estrategia metodológica tuvo como tipo de investigación cualitativa de nivel descriptivo, y método documental, al abordar la participación ciudadana en clave de

Citación del artículo: Urrego, G. (2017). Interdependencias y rupturas de la participación y planeación del territorio en Colombia, a partir de 1991. Revista Katharsis, N 23, enero-julio 2017, pp.236-259, Disponible en http://revistas.iue.edu.co/index.php/katharsis 
planificación territorial a escala local. El instrumento de recolección de la información fue ficha bibliográfica. La investigación considera dos fases: i) revisión especialmente de normatividad y documentos en bases de datos del Departamento Nacional de Planeación ii) análisis de contenido de las fuentes a través de categorías de análisis como territorio, participación ciudadana y planificación territorial.

\section{Resultados}

\section{$\underline{\text { La participación en la planeación del territorio }}$}

La dinámica contextual que envuelve la planeación territorial y la participación en el municipio colombiano es a través de concepciones de resignificación y renovación de exigencias como: i) sociales: por medio de relaciones y asociaciones entre la población y construcción de lo público ${ }^{4}$; ii) político: dado en el encuentro de intereses tanto de la administración municipal, los privados (en general de corte económico) y los colectivos (organizaciones civiles, sociales etc); y iii) temporal: en cuanto a la delimitación del tiempo y su relación con el cumplimiento de objetivos, metas e indicadores de gobierno. Todo ello pone en tensión el hacer de la administración municipal, en la medida que está condicionada por la racionalización jurídica y austeridad del gasto público, y esto con frecuencia, determina la planeación, la participación y las políticas sobre el territorio cuya aplicación a través de regulaciones requiere una conceptualización jurídica sobre ordenamiento territorial. Sostiene Massiris (2006, citado por Carrión, 2008: 145-146):

Este concepto (ordenamiento territorial), que se acuña en Europa a mediados del Siglo XX, se empieza a entender desde allí como una disciplina científica, una técnica administrativa y una política para el desarrollo equilibrado de las regiones y la organización física del espacio, mientras que en Latinoamérica éste se ha asumido principalmente como un desarrollo de técnicas de planificación de usos del suelo, planificación ambiental y/o planificación

\footnotetext{
${ }^{4}$ La historia de lo público y privado la trata Hannah Arendt en su texto La condición humana (2005). Además, lo público emerge de la sociedad civil, en la consecución de un espacio compartido y en un contexto de promesa democrática. A su vez, un encuentro articulador y generador de relaciones no jerárquicas, de dominación o subordinación del interés particular. Lo público no sólo alude a lo estatal, sino a una deliberación colectiva de prácticas sociales, culturales y políticas en tensión. Para Adrián Gurza (1998, p. 183), "Lo público es una dimensión social que obliga al Estado a salvaguardar un conjunto de intereses considerados como prioritarios por la sociedad. Más propiamente, lo público es una dimensión social impuesta al Estado por la sociedad bajo una determinada correlación de fuerzas, en la que ésta consigue poner al margen de la lógica del mercado un complejo de tareas socialmente necesarias para la reproducción y desarrollo de la sociedad como un todo. Al interior de lo público quedan resguardados los intereses comunes de la sociedad, por lo que es una dimensión que excluye al mercado en la racionalidad de su dinámica interna".

Citación del artículo: Urrego, G. (2017). Interdependencias y rupturas de la participación y planeación del territorio en Colombia, a partir de 1991. Revista Katharsis, N 23, enero-julio 2017, pp.236-259, Disponible en http://revistas.iue.edu.co/index.php/katharsis
} 
socioeconómica, que se desarrollaron en el continente desde la segunda mitad del siglo XX.

La participación hace parte de una sociedad pluralista y social, no solo comprende el sistema representativo tradicional del pueblo que delega poder de decisión en representantes. Como señala Papini (1979) que la participación es una expansión del hombre sobre sí mismo en relación con los otros, es decir, es la apertura al otro, que provoca un estímulo social, que tiende a convertirse en una contestación recíproca, responsable, digna y del hombre en devenir en colectivo. En esto último, la participación es consciente y ofrece respuestas a la construcción del hombre y decisiones que miran el bien común. Indica Papini (1979: 152):

(...) es la participación es en efecto, ponerse en camino a la búsqueda del otro, de todos los otros de los cuales somos una parte. La noción de participación conduce a la idea de comunidad

En la lógica y finalidad democrática, la participación no es simplemente una política e idea de delegación, sino de reconocimiento de la tensión entre el hombre y las colectividades en la elaboración y ejecución de decisiones administrativas y fiscales en y para lo público. Esto supone, la acción de lo público no como finalidad y posición que asume los ciudadanos y las colectividades para la búsqueda de su propio bien, sino permanecer en lo público como una incesante construcción. Por consiguiente, la participación como la superación de la centralización del poder de decisión manifiesto en la delegación para la ejecución de decisiones, se basa en un pacto social de autorregulación de poderes entre quienes proponen, hacen, solo son informados y son beneficiarios pasivos. La participación como poder político coordina los intereses de la sociedad y el mercado para regular y articular las fuerzas de poderes contrarias y la producción y distribución de bienes. Añade Vargas (2007:12):

Las relaciones entre el Estado y el Mercado pueden estar orientadas por la gobernabilidad democrática, que sirve de sustento a la gestión social mediante la cooperación de las instituciones nacionales que regulan los mecanismos de distribución equitativa de los recursos en las localidades. La asignación del gasto público, es uno de los problemas que obstaculizan la gobernabilidad descentralizada en relación con los conflictos distributivos. Los conflictos distributivos obstaculizan la descentralización de la gobernabilidad.

Es importante resaltar que, la participación como señala Gómez et al. $(2012$, p.53) es "la demarcación del rol de los ciudadanos en la construcción de proyectos y acciones que mejoren positivamente sus condiciones de vida". Así, la participación se sitúa en el ideal democrático en el que los ciudadanos inciden en la toma de decisiones colectivas a escala local, como compromiso social de la deliberación pública. La acción de los ciudadanos como un colectivo mediado por intereses, decisiones y relaciones de poder, en los cuales se considera elementos: reflexión continúa del interés general, la gestión local para superar la visión de la participación como la mera inscripción de votos, hecho presente en la democracia representativa del sistema

Citación del artículo: Urrego, G. (2017). Interdependencias y rupturas de la participación y planeación del territorio en Colombia, a partir de 1991. Revista Katharsis, N 23, enero-julio 2017, pp.236-259, Disponible en http://revistas.iue.edu.co/index.php/katharsis 
político colombiano y, en la aprobación o no de planes e iniciativas de actores gubernamentales, políticos, económicos, socioculturales y ambientales. Sugiere Patiño (2008:269):

La inequidad en la asignación de recursos para la atención de los problemas ambientales en las diferentes localidades de las ciudades, hace necesario que se incremente la capacidad de gestión en las localidades a través de la participación comunitaria activa y la inversión suficiente que permitan revertir los impactos ambientales negativos causados por las dinámicas de las ciudades.

Ahora bien, la interdependencia entre la planeación territorial y la participación evoca y sugiere, según la Constitución Política Colombiana de 1991, un mecanismo de consulta, en el artículo 339, en el que las autoridades locales solicitan a la ciudadanía su visión en temas de plan de desarrollo y ordenamiento territorial, pero sin poder vinculante y decisivo en la toma de decisión. Aquí se encuentran los consejos de planeación compuestos por representantes de todos los sectores: económico, social, ecológico, cultural, comunitario entre otros. Además, la relación entre la planeación territorial y la participación es reconocer los procesos de toma e implementación de decisiones de carácter jurídico, técnico, administrativo, político, social y económico que necesariamente evoca la identificación de actores que tienen la capacidad de incidencia sobre el territorio. Contextualiza Llorente (2009:108).

La baja interacción espacial entre los municipios puede limitar en el contexto colombiano, con algunas excepciones, el alcance de la integración regional como estrategia para promover el desarrollo local. Esto sugiere que las políticas de desarrolla regional exitosas deben adoptar una mezcla de enfoques. En algunos casos pueden impulsar cambios estructurales que fomenten una mayor interacción, y en otros, reconociendo está limitación, adoptar mecanismos de transferencia de recursos.

Por otra parte, la planeación territorial (ver gráfica 1) tiene en cuenta lo estratégico como la instalación de objetivos a alcanzar que se establecen y que son condicionados por las relaciones sociales, comerciales, económicas, las costumbres, lo cultural en todo el territorio. La planeación parte de tres pilares: lo que se debe hacer, lo que es necesario hacer y lo que es posible hacer. A su vez, lo estratégico permite la vinculación entre la administración del territorio y la participación a partir de la democratización de la gestión pública local.

Citación del artículo: Urrego, G. (2017). Interdependencias y rupturas de la participación y planeación del territorio en Colombia, a partir de 1991. Revista Katharsis, N 23, enero-julio 2017, pp.236-259, Disponible en http://revistas.iue.edu.co/index.php/katharsis 


\section{Gráfica 1.}

Determinantes en la planificación y el ordenamiento del territorio en el municipio colombiano

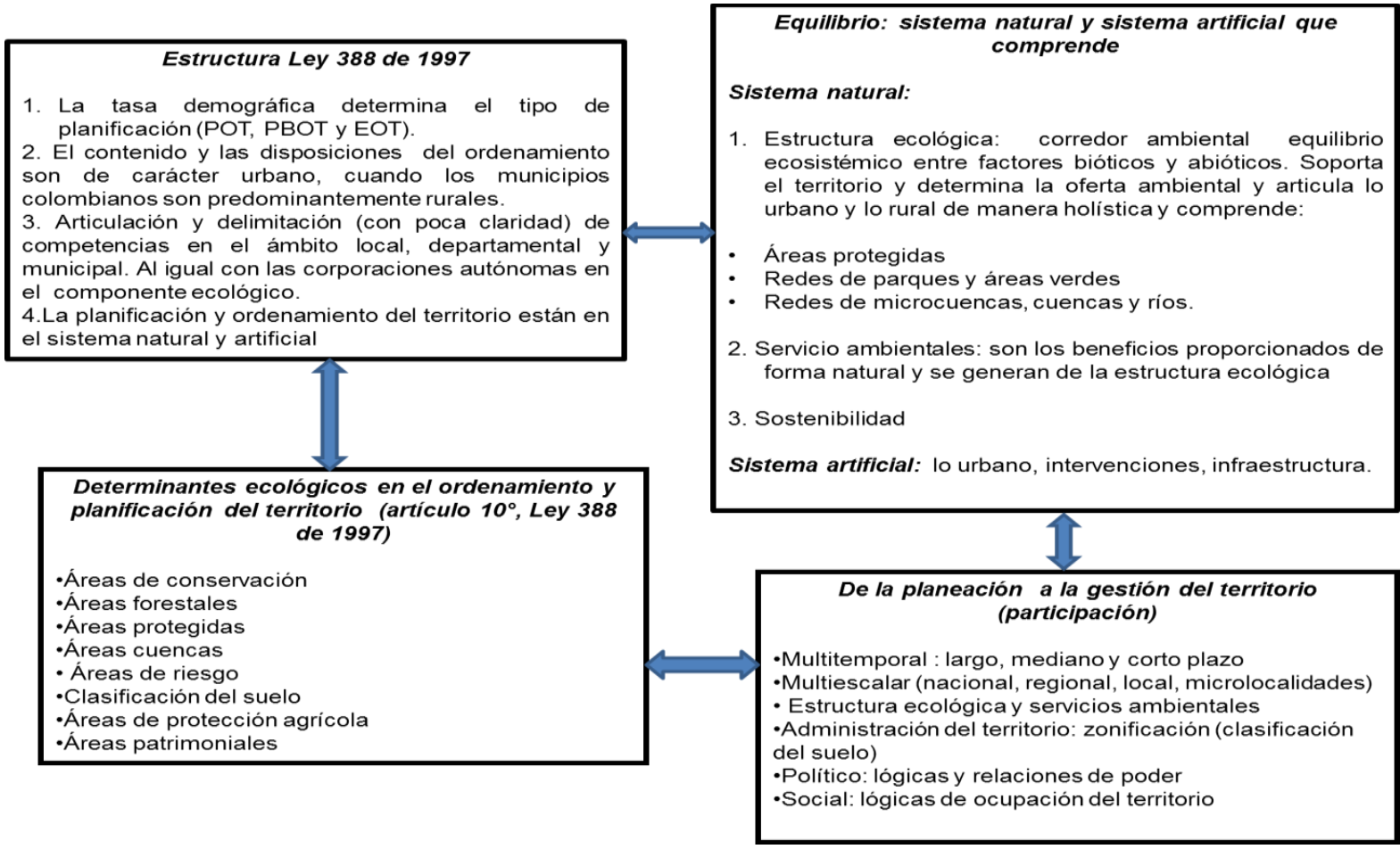

Fuente: Elaboración propia.

Desde esta perspectiva, las interdependencias entre la planeación territorial y la participación se centran en anticiparse a futuros deseados que son posibles en concesos y en la incidencia operativa de la administración municipal, para identificar (a través de la realización de un mapa) cuáles son los intereses sociales, económicos y políticos por parte de la población del municipio, y que en el territorio son visibles. Ahora bien, las rupturas entre la planeación territorial y la participación radican en el carácter procesual, es decir, la naturaleza jurídica que caracteriza todo proceder técnico de la administración local en materia de planeación, especialmente en actuaciones urbanas, establece una lógica reglamentada de entender y disponer del territorio (usos del suelo funcionales), esto se distancia muchas veces de la realidad socio espacial de la población. A propósito, plantea la Escuela de Hábitat - CEHAP- (2005:36):

Las Actuaciones Urbanas Integrales o macro proyectos son operaciones de gran escala e indiscutible impacto en la estructura y la organización espacial urbana, en el crecimiento general de la ciudad o la región y en la calidad de vida de la población. Deben integrar al menos un componente de gestión del suelo con dos componentes de acción sectorial y prever la actuación conjunta y concertada del sector público con el sector privado. Deben reunir las siguientes características: Gran impacto local o supramunicipal, Manejo integral de distintos temas sectoriales, Concertación de diversos actores públicos y privados.

Citación del artículo: Urrego, G. (2017). Interdependencias y rupturas de la participación y planeación del territorio en Colombia, a partir de 1991. Revista Katharsis, N 23, enero-julio 2017, pp.236-259, Disponible en http://revistas.iue.edu.co/index.php/katharsis 
Acción interinstitucional y concurrencia de distintos niveles de administración. Compromiso del municipio, como líder y gestor del proyecto.

Las finalidades del bien común territorial que pretende la participación a escala local, en cuanto a la permanente configuración de intereses individuales y colectivos no solo de los ciudadanos, sino de toda la población, y, como proceso continuo e inacabado, de concesos y disensos de intereses, memorias, vivencias y normativa del territorio. La participación a partir de un ser y saber hacer, tanto institucional como ciudadano y colectivo, retoma la comunicación, la información, recuperación y diálogo de saberes previos y formales, con el fin de encontrar un sentido ampliamente compartido de los gobiernos locales y la población frente al territorio, también en clave de sostenibilidad ambiental, que logre gradualmente interponerse a obstáculos individuales y colectivos de apatía, miedo a lo desconocido y exclusión. Complementa Cadavid (2009:263-264):

Fortalecer más la perspectiva regional y el sistema de ciudades contribuye, en parte, a la pretendida sostenibilidad ambiental y equilibrio socio espacial en la ocupación del territorio, en atención a los principios de la capacidad de carga y resiliencia eco sistémica; por tanto, 'los bordes de las ciudades', esa ruralidad próxima, debe ser comprendida como franja estratégica de protección y configuraciones múltiples, sujeto de compensación o reparto equitativo de beneficios, por los bienes y servicios que intercambia con los sistemas urbanos en su conjunto. Por último, la relevancia de los procesos de participación social en políticas públicas es la oportunidad de realimentación entre perspectivas técnicas y culturalistas, el empoderamiento de dichas comunidades sobre su devenir y la coincidencia de voluntades entre gobernantes y gobernados, es condición de gobernabilidad sobre dichos territorios.

Por otra parte, la tensión entre planeación territorial y participación se centra en la planeación formal, centralizada, racional, técnica y coyuntural, en cuanto es positivista porque busca resultados; funcionalista, determinada por insumos, procesos y productos cuantificables; hegemónica, generalmente se centra en un solo actor, quien organiza y alinea todas las acciones y la toma de decisiones políticas, sociales, culturales y económicas hacia una única finalidad. A pesar de que, con frecuencia, es necesario facilitar el encuentro de lenguajes técnicos (ver gráfica 2), a través de un proceso pedagógico que implica: I) motivación en los todos los actores involucrados en la planificación del territorio; II) procesamiento e intercambio de la información trasmitida por todos los actores involucrados del gobierno local y la población, que abarque los conflictos de poder, dependencia de recursos naturales y económicos, falta de voluntad política; y III) el reconocimiento de la carga simbólica hacia el territorio y los sistemas territorialesurbanos. Añade Boada \& Toledo (2003:77-78):

El mantenimiento de la complejidad de los sistemas urbanos se fundamenta en la explotación de recursos ubicados en ámbitos más o menos lejanos. El agua, los alimentos, la electricidad, los combustibles, etc., tienen que hacer recorridos muy largos en poco tiempo. Ello desemboca en la construcción de grandes infraestructuras en el territorio que acaban afectando a otros sistemas. Es decir,

Citación del artículo: Urrego, G. (2017). Interdependencias y rupturas de la participación y planeación del territorio en Colombia, a partir de 1991. Revista Katharsis, N 23, enero-julio 2017, pp.236-259, Disponible en http://revistas.iue.edu.co/index.php/katharsis 
el funcionamiento de la ciudad interfiere en el medio de dos maneras: por una parte, en la producción de recursos para su mantenimiento y, por otra, en la construcción de los canales necesarios para que estos recursos lleguen a ella.

Lo anterior permita superar el modelo técnico de la acción gubernamental y la poca e incidente participación de la población de los municipios colombianos. Este punto de encuentro, como se indica en la gráfica N 1, radica en la toma de decisiones y armonización de intereses presentes en la construcción social, política e histórica determinada por el contexto del municipio. Así mismo, resignificar la planeación territorial desde la participación exige el reto de una relación de confianza entre el Estado y la población, a partir de la transparencia en la construcción de lo colectivo, reconocimiento de otros medios no convencionales de comunicación y producción de información de la población, autogestión, intervención consciente y comprometida de todos (administración municipal y los diferentes actores sociales, políticos, económicos) donde prime el interés general sobre el particular.

\section{Gráfica 2.}

Planeación territorial y participación en los municipios colombianos

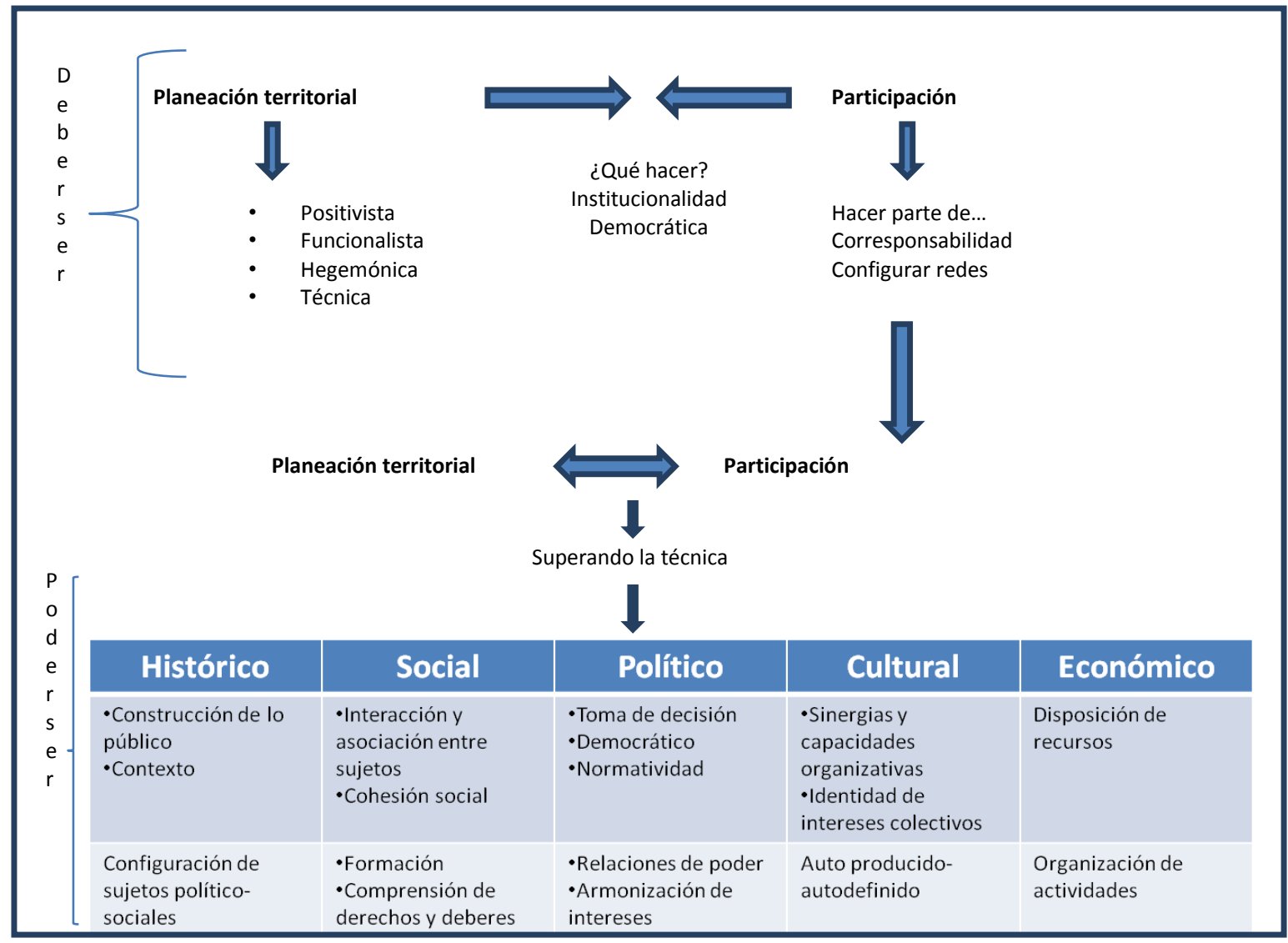

Fuente: Elaboración propia.

Citación del artículo: Urrego, G. (2017). Interdependencias y rupturas de la participación y planeación del territorio en Colombia, a partir de 1991. Revista Katharsis, N 23, enero-julio 2017, pp.236-259, Disponible en http://revistas.iue.edu.co/index.php/katharsis 
En esa medida, la planeación territorial y la participación son condicionadas por rasgos característicos que se encuentra en la concertación de intereses y supere la técnica, esto es, tanto la administración municipal como la población (organizaciones sociales y comunitarias) demuestren credibilidad crítica y reflexiva, posición propositiva, pensamiento y acción, con fines de preservar y mejorar condiciones de vida. A su vez, las distintas fuerzas socioculturales, políticas y económicas en función de los intereses acordados colectivamente, con el fin de mantener y transformar los sistemas de organización social y política en la configuración del territorio. En cierto modo, lo anterior se abordaría bajo un enfoque de intencionalidad, con características como: i) de base social y ciudadana en el relacionamiento y asociatividad entre actores institucionales, sociales, políticos y económicos dotados de sentido y significados, y ii) democrático a través de la deliberación política, el diálogo, la comprensión y construcción de lógicas territoriales colectivas, es decir: ¿cuál es la finalidad de toda actuación urbana y a quiénes beneficia? Ejemplariza Ibarra (2007:38):

La lectura de la Carta europea sobre ordenamiento territorial nos informa que el ordenamiento territorial es una disciplina con carácter interdisciplinario, cuyo objetivo es el desarrollo equilibrado de las regiones y la organización física del espacio según un concepto rector. En América Latina el orden territorial es una política de los estados para superar los desequilibrios espaciales del desarrollo ligada a los procesos de planificación económica.

\section{Discusión}

Territorio vínculo entre la planeación y la participación desde el ordenamiento territorial en Colombia

El territorio en esencia es la problematización de todo el proceder e intereses administrativos, políticos, económicos, sociales y culturales en el municipio. Dicha problematización permite poner en cuestión hechos relevantes como: ¿para qué y bajo que lógicas de ocupación, apropiación y uso responden los diferentes actores políticosinstitucionales y comunitarios en el territorio?¿Cuáles y cómo se articulan las relaciones de poder institucionales, ciudadanas y no legales dentro del territorio y en el funcionamiento de la sociedad?, Y por último, ¿cuál es la incidencia de la sociedad en la configuración de las realidades y en las relaciones de poder territorial? Señala Peñaranda (2008:231):

El desarrollo territorial (amplia expresión que incluye el desarrollo de micro localidades, tales como comunas, y de meso localidades, tales como provincias o regiones), se refiere a procesos de cambio socioeconómico, de carácter estructural, delimitados geográficamente e insertos en un marco configurado por sistemas económicos de mercado, amplia apertura externa y descentralización de los sistemas de decisión.

Citación del artículo: Urrego, G. (2017). Interdependencias y rupturas de la participación y planeación del territorio en Colombia, a partir de 1991. Revista Katharsis, N 23, enero-julio 2017, pp.236-259, Disponible en http://revistas.iue.edu.co/index.php/katharsis 
La gráfica $\mathrm{N} 3$ evidencia la necesidad de dimensionar el imaginario que tienen los pobladores y el gobierno local del territorio, como asunto de configuración de lo público, soporte material y producción sociocultural, construido en las prácticas cotidianas como actuaciones, significados, valores, experiencias, emociones (sentimientos) de quienes hacen parte de él. $\mathrm{O}$ como plantea Bozzano, "el territorio es un objeto complejo, que existe en la medida que nosotros - sujetos - lo "construimos" combinando nuestro concreto real con nuestro concreto pasado" (Bozzano, 2000:56). A propósito de las prácticas en el territorio, añade Michel De Certeau (2007, XLV): "estas son operaciones multiformes y fragmentarias, relativas a ocasiones y detalle, insinuadas y ocultas en los sistemas de los cuales estas operaciones constituyen los modos de empleo, y por tanto desprovistas de ideologías o de instituciones propia, y obedezcan a determinada regla". Por su parte, señala Lindón (2006:372): "pueden referirse a diferentes tipos de lugares... según se la práctica y su temporalidad, la noción de quedarse o permanecer es más o menos fija en el espacio".

De esta manera, el territorio está configurado en prácticas sociales, culturales, políticas y económicas en las que están presente la forma de habitar de pobladores, los intereses y deseos sociales que configura una trama de relaciones entre geografía (condiciones físico-espaciales), infraestructura (sistema artificial) y vivencias espaciales. Esto último en cuanto a la construcción y el reconocimiento de saberes y experiencias de los pobladores, dada en las relaciones sociales, culturales y políticas como formas de habitar, apropiar, significar y ocupar territorios específicos; relación de doble vía entre el territorio hacia la sociedad y la sociedad hacia el territorio. El territorio como categoría de intervención y de acción, a su vez, como producción histórica de espacio vital donde la cotidianidad tiene impacto en características físicas, culturales y de regulación política (leyes). Indica Moreno (2002:8):

A partir de los ordenamientos legislativos que definen funciones a los entes territoriales, comienza en el país a diferenciarse la planeación del desarrollo económico y social de la planeación física y del ordenamiento territorial, aunque alguna legislación actual mantiene terminologías de leyes anteriores.

El territorio como el espacio de uso (satisfacción de necesidades humanas), cambio (lo trazable) y significativo (la experiencia y apropiación). Abordado desde, como se interpretaría en Lefébvre (1974) en su texto "la producción del espacio", en prácticas socioculturales,

\footnotetext{
${ }^{5}$ Como señala Urrego $(2014$, p. 32) en sus tesis de maestría "Procesos de HABITAR desde las relaciones intersubjetivas a través de los imaginarios y las acciones colectivas. barrio Alejandro Echavarría 1950-2012" Al respecto Lefébvre (1974) en su concepción teórica del espacio, argumenta que el espacio se divide en tres nociones; la primera noción, es el espacio percibido, en el cual la materialización de las formas concretas, producto de la intervención de los sujetos, le otorgan existencia por medio de un proceso histórico. El segundo espacio es el concebido, aquel imaginado, significado y representado en los pensamientos del sujeto (s) que interviene en él, a través de experiencias, acciones y costumbres. Aquí el espacio es receptáculo de la cotidianidad de pensamientos y prácticas individuales -colectivas. El último espacio que Lefébvre señala es el espacio vivido como constituyente de una relación simultanea de lo imaginado, la materialización y la experiencia entre los sujetos, como expresión Citación del artículo: Urrego, G. (2017). Interdependencias y rupturas de la participación y planeación del territorio en Colombia, a partir de 1991. Revista Katharsis, N 23, enero-julio 2017, pp.236-259, Disponible en http://revistas.iue.edu.co/index.php/katharsis
} 
representaciones simbólicas, sentido de permanencia, pertenencia y aceptación colectiva de redes y flujos espaciales. A su vez, el territorio como soporte, configuración de la producción social e intercambio material y significativo de los pobladores del municipio, parte de un sentido del lugar (el terruño) y carga simbólica (aquí crecí, aquí muero, esta tierra es de mis antepasados) impregnada en los procesos socioculturales, políticos y económicos. Al tiempo, el territorio es concreción física delimitado y determinado por las formas en que se estructuran las relaciones políticas, económicas y socioculturales entre los pobladores con la oferta natural y artificial de la tierra.

\section{Gráfica 3.}

\section{Territorio}

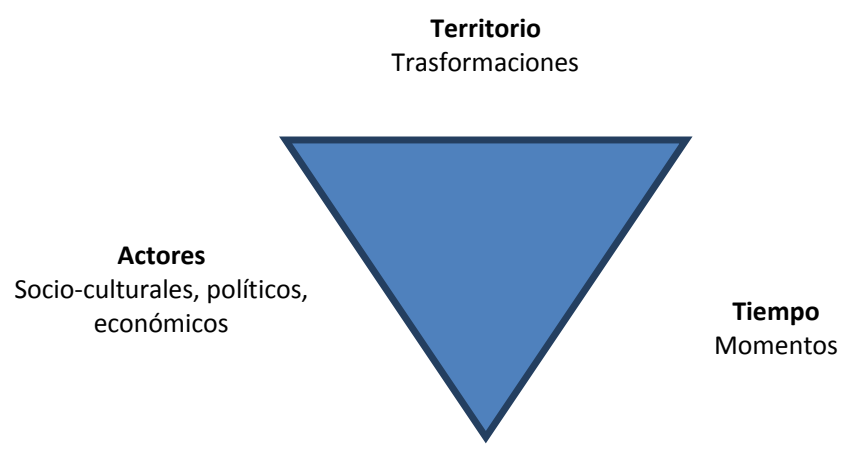

Fuente: Elaboración propia.

Por otra parte, Bozzano concibe el territorio como un "mapa de relaciones de intereses" (2000, p.118) delimitado, a su vez, como "un escenario donde los humanos entran en relación con los otros hombres y con objetos. Así mismo, el territorio es organizado y diferenciado en su uso material y ante todo social; sus límites son significativos, son hechos que otros sujetos del entorno reconocen como propios a él, donde habitarlo es partir de la cotidianidad histórica, social, política, económica y cultural." A propósito, es necesario vincular el territorio y la participación en el plan básico de ordenamiento territorial en el municipio colombiano desde repensar cuál es el modelo territorial a seguir, esto es: ¿qué proyectos urbanos e inmobiliarios se tienen para el municipio, y cómo estos se armonizan con la memoria y las experiencias de vida que los pobladores tienen del territorio? Argumenta Escallón (2006:113):

Existe una concepción generalizada de que el territorio en sí mismo constituye un sujeto heterogéneo de difícil agregación cooperativa, en el que hay un estímulo tácito a las adiciones individuales, sin marcos globalizantes que

del lenguaje a través de vínculos de trasferencia de sentido y carga simbólica de cercanías, lejanías, de nombrarlo y sentirlo.

Citación del artículo: Urrego, G. (2017). Interdependencias y rupturas de la participación y planeación del territorio en Colombia, a partir de 1991. Revista Katharsis, N 23, enero-julio 2017, pp.236-259, Disponible en http://revistas.iue.edu.co/index.php/katharsis 
resultan en un desarrollo de los datos inconexo y muchas veces descoordinado y por tanto, incoherente. Esta forma de abordar el proceso reflejada tanto en acciones institucionales como individuales, ha traído múltiples problemas, no solo por el fomento del aislacionismo sino por la costosa duplicidad de esfuerzos que estas prácticas indefectiblemente acarrean. La experiencia de muchos países ha demostrado que esta concepción puede ser superada con creces, mediante estrategias que involucran acciones a nivel nacional, institucional e individual.

Al tiempo que el territorio municipal se piensa como autoproducción, construcción social simbólica y material, aglutinador de deseos y relaciones de poder de los múltiples actores y realidades que inciden en la toma de decisiones político-administrativas. Esto sugiere interrogar todo quehacer político-administrativo sobre el territorio: ¿la planeación y la participación es solo la instrumentalización de la norma (ley 388 de 1997), a su vez, se suscribe a políticas de gobierno cortoplacistas? o es inexcusable incorporar en la planeación y la participación relaciones y lógicas territoriales a largo plazo, como: derechos territoriales a la propiedad, uso colectivo y gestión de la tierra; propiedad, uso y apropiación colectiva del agua; dirimir conflictos por recursos minero-energéticos, afectaciones territoriales por infraestructura agroindustrial y urbana a escala local y nacional; por último, formas de autoconstrucción barriales - vivienda. En otro sentido, argumenta Asensio (2006:135-136):

De todas las prioridades políticas que declaran los alcaldes cuando hacen balance de su gestión municipal, el urbanismo y las infraestructuras son temas que siempre están presentes. Una de las claves de la planificación local se encuentra en la ordenación del territorio. El término municipal se encuentra atendiendo a la tradicional clasificación del suelo urbano (consolidado o pendiente por urbanizar) y no urbanizable. También son fundamentales las calificaciones de ese suelo en distintos usos: residencial, industrial, equipamiento deportivo o social, centros educativos, viales, zonas verdes, etc.

De ahí, hay una tensión entre la racionalidad, homogeneidad y tecnicidad de la planeación institucional con los procesos sociales, culturales, políticos y económicos. Los primeros son de naturaleza racional y los segundos parten de lógicas no convencionales. Esta tensión se evidencia en el territorio municipal y exterioriza múltiples formas de ocupación, uso y apropiación del suelo, contradictorias entre sí, que deben encontrar una salida en el debate, a partir de ¿qué beneficios y a quién (es) beneficia el ordenamiento del territorio? Contextualiza Rengifo R. (2012:13-14):

La evolución que tuvo la planeación se manifestó en la forma como se fue incorporando a través del tiempo pasando de una planeación económica a la planificación regional y territorial; de la planeación física urbana y rural, a la planeación integral; de la planeación técnica a la planeación participativa; de la planeación indicativa a la planeación direccionada.

Citación del artículo: Urrego, G. (2017). Interdependencias y rupturas de la participación y planeación del territorio en Colombia, a partir de 1991. Revista Katharsis, N 23, enero-julio 2017, pp.236-259, Disponible en http://revistas.iue.edu.co/index.php/katharsis 
Es necesario, por un lado, flexibilizar la planeación y direccionarla en el municipio colombiano a para articular las múltiples formas de percibir y vivir el territorio (ocupación, uso y apropiación) por parte de todos los actores. Ello implica reconocer los imaginarios, las creencias, las formas de hacer territorio en perspectiva histórica, es decir, el territorio no como un hecho construido, sino que su configuración obedece a procesos que van desde cómo se llega a él, la tendencia de la tierra, hasta la configuración de organizaciones culturales y estructuras sociales. Por otro lado, la participación también debe ser deliberante, democrática y propositiva, en cuanto presente propuestas de conservación y renovación urbana-rural que influyan en la toma de decisiones y ordenamiento del territorio. En especial, la participación debe contribuir a superar la tensión entre lo urbano-rural que ha sido en clave de la funcionalidad planificadora de uso del suelo, en la medida que lo urbano no determine la ocupación y el poblamiento del municipio, y lo rural se abarque más allá de la conservación, del derecho a la propiedad y de las unidades productivas agrícolas. Indica Agudelo (2010:27):

No se ha estudiado integralmente, desde el enfoque sistémico, las relaciones urbano-rurales, por lo que no se considera la oferta ambiental actual del territorio sobre el cual se asienta la ciudad. Es por eso que lo rural, en el planeamiento, no pasa de ser un lugar a la espera de la urbanización, y pierde su real dimensión como sustento del bienestar urbano.

\section{Horizontes de articulación entre planeación territorial, participación y territorio}

Un horizonte de articulación entre planeación territorial, participación y territorio en el municipio colombiano parte de considerar el interés general sobre el particular. En esa medida, el ordenamiento territorial es un ejercicio de planificación que centra todo su accionar en realzar el territorio a escala de integración regional. Exponen CorAntioquia y Grupo Territorio y Ambiente - TEAM- (2005:489-490):

La dimensión urbano-regional toma como factores de mayor dinamismo en los procesos de reconfiguración espacial de la jurisdicción, el estado de las infraestructuras de conectividad interregional y de producción hidroenergética, para tenerlas presentes como estímulos -tendencias- en la reorganización urbano-regional, en tanto constituyen megaproyectos. Esta dimensión permite aproximarnos a la estructura -por dinámica e integración- del sistema territorial regional, estableciendo una interpretación de los procesos de centralidad, funcionalidad, articulación, desequilibrio, marginalidad del actual modelo de configuración urbano-regional.

Colombia se caracteriza por ser un país en el cual la cuestión regional no se ha resuelto. Sobre la integración regional se han comentado toda serie de problemas tales como la inequidad, las limitantes del sistema democrático y la ausencia del Estado en la mayoría de los territorios

Citación del artículo: Urrego, G. (2017). Interdependencias y rupturas de la participación y planeación del territorio en Colombia, a partir de 1991. Revista Katharsis, N 23, enero-julio 2017, pp.236-259, Disponible en http://revistas.iue.edu.co/index.php/katharsis 
que componen la Nación ${ }^{6}$. Si se exploran estos argumentos a la luz de las realidades regionales, se puede llegar a concluir que parte muy importante de las entidades e identidades territoriales continúan funcionando bajo una lógica territorial, bien sea por el estado de aislamiento geográfico, o bien por los procesos históricos y de violencia en los que se ha desarrollado Colombia, en la que ciertos territorios considerados de influencia insurgente o contrainsurgente son excluidos de las lógicas generales tanto de desarrollo económico, como del manejo político - administrativo. Indican Muñoz \& Holguín (2001:122):

Este nuevo contexto permite una transformación radical del papel que deben jugar las autoridades administrativas en el fomento del desarrollo local. Así, entonces, de simples agentes concentrados casi que exclusivamente en la gestión de sus propios recursos y en la prestación de unos determinados servicios públicos, deben pasar a convertirse en agentes catalizadores del conjunto de iniciativas provenientes de los diferentes actores sociales, económicos y políticos locales; lo cual obliga a asumir nuevas responsabilidades como líderes en sus respectivos territorios de influencia.

El otro horizonte de articulación está en la visión amplia que sobre el territorio se debe considerar, más allá de lo físico-espacial como expresión cargada de memoria, de construcción social y cultural, que produce y es productor de relaciones sociales, culturales y productivas. Además, territorio cargado de sentido y materialidad (construcción, apropiación, reconocimiento de lo que se llama terruño). Así mismo, como se evidencia en Gómez y Vélez (2011) las dinámicas que se tejen en el territorio están llenas de significados, como la territorialidad, es decir, lo inmaterial del territorio y articulación de esferas sociales-culturales, económicas, políticas y ambientales. Analizan Rojas \& Álvarez (2011:27):

En este paradigma, el gobierno también se caracteriza por su papel de gestor, pero no de equipamientos y servicios públicos, sino de gestor relacional. Esta gestión relacional, o gestión de la estrategia de los actores y de la participación ciudadana en un territorio, tiene como objetivo específico la mejora de la capacidad de organización y acción del territorio o de la construcción colectiva del desarrollo, que permiten, como se señalará, conseguir un mayor impacto en el progreso económico y social.

Otro horizonte de articulación entre planeación territorial, participación y territorio es el reconocimiento de dinámicas contextuales en el que la participación reconoce otros saberes, formas de conocimiento sobre el territorio, y la planeación institucional ingresa, propicia, fortalece y se adhiere a la armonización de intereses individuales y colectivos en los niveles

\footnotetext{
${ }^{6}$ Ver Botero, M. H. (2003). Desarrollo regional e internacionalización de las regiones. Documento de investigación $\mathrm{n}^{\circ}$ 3. Grupo de Estudios Regionales Universidad Del Rosario y Boisier, S. (2001). Desarrollo (Local): ¿De qué estamos hablando? Buenos Aires: Editorial Homo Sapiens

Citación del artículo: Urrego, G. (2017). Interdependencias y rupturas de la participación y planeación del territorio en Colombia, a partir de 1991. Revista Katharsis, N 23, enero-julio 2017, pp.236-259, Disponible en http://revistas.iue.edu.co/index.php/katharsis
} 
organizativos y de participación social. Esto como un conocimiento situado, tanto para la administración municipal como para la misma población. Así, reconocer y afrontar situaciones conflictivas y asumir el reto de generar confianza entre todos los actores para la toma consensuada de decisiones, que implica transformaciones sobre el territorio como medio y fin de relaciones de poder institucional, político, económico y social. Contextualiza Torres (2004:4):

En suma, las experiencias de gobernabilidad territorial en los cuatro países andinos son indicativas de una tendencia de creciente interés por el manejo público de los territorios subnacionales, en la que los gobiernos locales tienden a constituirse en el núcleo de la gobernabilidad del territorio y de la gobernanza ambiental. La mayoría han enfatizado en el aspecto institucional creando nuevas instituciones para la gestión pública territorial, pero no han avanzado suficientemente en la dimensión económica, así, aunque están consolidando su institucionalidad requieren avanzar hacia la productividad del territorio y su articulación al mercado para lograr la finalidad del desarrollo territorial, esto es la superación de la pobreza en un marco de oportunidades compartidas por sus habitantes.

Otro horizonte de articulación entre planeación territorial, participación y territorio considera la planificación física en la asignación de los usos de la tierra, localización de la población y actividades económicas en pro del mejoramiento social, en cumplimiento del artículo 311 de la Constitución de 1991. Así, con la entrada en vigencia del orden local y regional, más que perder fuerza en apariencia, lo que ha ganado el Estado local, es el poder de representación y acción por cuanto en la actualidad están asumiendo paulatinamente acciones, poderes, decisiones y políticas de corte estatal sobre el uso y ocupación territorial. Es decir, ha sido trasladada la presencia del Estado de corte central a una representación territorial más cercana, reflejada y caracterizada por las instituciones locales como el municipio. Señala Espín (2009: 3-4):

La gobernabilidad depende de una combinación virtuosa de tres elementos centrales: a) el fortalecimiento político - institucional democrático, b) el desarrollo socioeconómico y la integración social: la generación de políticas que satisfagan las necesidades básicas del conjunto de la población, y c) La promoción de un clima internacional que privilegie la resolución pacífica y negociada de conflictos. Todo lo anterior facilitará la convivencia democrática. Relacionar la gobernabilidad con convivencia democrática destaca lo que parece más invisible en la discusión prevaleciente, es sacar a la luz a los actores de la gobernabilidad.

Por otra parte, el horizonte de articulación entre la planeación territorial, participación y territorio radica en la gobernabilidad. Como se señala en Ibarra (2001), la gobernabilidad parte de un fenómeno dinámico que se establece entre gobernados y gobernantes, donde movimientos e instituciones marchan hacia la construcción de la sociedad, cumplimiento de expectativas y Citación del artículo: Urrego, G. (2017). Interdependencias y rupturas de la participación y planeación del territorio en Colombia, a partir de 1991. Revista Katharsis, N 23, enero-julio 2017, pp.236-259, Disponible en http://revistas.iue.edu.co/index.php/katharsis 
metas; por parte del estado son medibles en eficacia y eficiencia, y por parte de la población, en calidad de vida. Explica Revesz (2005:7):

La gestión democrática entendida como el proceso en el cual las autoridades municipales y regionales despliegan sus capacidades para articular e involucrar a la sociedad civil en una propuesta de desarrollo concertada, estableciendo mecanismos y espacios para su participación en la toma de decisiones de las prioridades del desarrollo local y regional.

Precisamente el municipio colombiano, como estado local, es un agente facilitador, dinámico y flexible frente a procesos de evaluación de los niveles de aceptación, gestión, actuaciones o decisiones gubernamentales en materia de integración de lo urbano y lo rural, valor del suelo, cobro y de destinación de recursos para mejorar la calidad de vida. En estos se juega en gran medida no solo al electorado, sino el cambio de rumbo en la dirección del municipio como médula para el análisis de la condición del gobierno en la gestión y administración del territorio. Es decir, ¿cómo administramos el territorito y para qué y quiénes lo administramos?

\section{Conclusiones}

La participación, en el marco de la Ley Estatutaria de Participación Democrática 1757 del 6 de julio de 20157, en clave de planificación territorial en el municipio colombiano abarca características como: inclusión (apertura a otras voces y otros sectores), incidencia (contribuir a acciones colectivas), deliberación (debates, consensos y disensos), apertura al diálogo de saberes y aprendizaje colectivo que permitan disminuir asimetrías en la producción y circulación de información y concentración de poderes territoriales. La participación un compromiso social de deliberación pública sobre la visión del territorio, que comprende su uso, cambio y su carga simbólica (el territorio significado). La participación alude a un proceso de representación de las colectividades, los concesos y disensos de los intereses anti-individuales, memorias, experiencias y vivencias territoriales. Ejemplifica Nerys (2011:143):

Respecto a la ciudadanía, se presentan situaciones disímiles por eje: como hemos visto, en ocasiones, los gobiernos han consultado con sus ciudadanos acerca de las obras a realizar y éstos han expresado su opinión de manera no conflictiva; en otras, los trabajos proyectados no han afectado mayormente la actividad habitual, por lo cual no han generado rechazos; otras veces, en cambio, la oposición de organizaciones ciudadanas es abierta.

\footnotetext{
${ }^{7}$ El artículo 86 de la Ley 1757 de 2015, establece la creación del Sistema de Participación Ciudadana para los entes territoriales especificados en la Ley. Un sistema es comprendido como un dispositivo de articulación de instancias, espacios, sujetos, recursos, instrumentos y acciones de la participación ciudadana, interpretación que se desprende de la función que le asigna la Ley al Consejo Nacional de Participación (artículo 80). Dicho sistema será liderado y puesto en marcha por el Consejo de Participación de la respectiva entidad territorial.
}

Citación del artículo: Urrego, G. (2017). Interdependencias y rupturas de la participación y planeación del territorio en Colombia, a partir de 1991. Revista Katharsis, N 23, enero-julio 2017, pp.236-259, Disponible en http://revistas.iue.edu.co/index.php/katharsis 
La participación promueve una democratización real, pero, también puede ser causa de parálisis en las decisiones en el poder político directo del ámbito local. Así, la participación en clave de panificación territorial se debe constituir en nuevas formas de representación de los intereses públicos territoriales, entre ellos: derechos territoriales a la propiedad, uso y gestión de la tierra; propiedad, uso y apropiación colectiva del agua; disputas por recursos mineroenergéticos, afectaciones territoriales por infraestructura agroindustrial y urbana a escala local y nacional; a través de asociaciones y grupos de la sociedad. Contextualiza Gaviria \& Arango (2007:55-56):

En términos generales la infraestructura se refiere a los elementos físicos necesarios para la prestación de los servicios requeridos por las actividades humanas que se desarrollan en un territorio. Es importante destacar que la tecnología y las infraestructuras eficientes constituyen instrumentos o medios para generar desarrollo y establecer y mantener flujos de intercambio; pero finalmente son las personas y las organizaciones, a través de relaciones de índole social, cultural y económica, las que permiten crear el esperado desarrollo y los ya mencionados nexos de integración a todas las escalas.

También considerar: conectividad ecológica de la región, desproporción entre la ocupación del suelo urbano y suelo de expansión programado, legalidad y legitimidad del modelo territorial propuesto, fragmentación ecológica del territorio, compactación del desarrollo urbanístico e industrial, preservación de la economía agropecuaria campesina, y justicia distributiva en la distribución de las oportunidades de búsqueda y captura de plusvalor y rentas de inversión privadas (Ministerio de Vivienda, Ciudad y Territorio, 2012). Añade Área Metropolitana (2010:172).

La importancia de aplicar y desarrollar mecanismos de intervención en el suelo con el fin de vincularlos en obras públicas y proyectos estratégicos, radica en que el Estado debe extremar sus esfuerzos para ser eficiente en el uso de los recursos públicos y recuperar las plusvalías que él mismo genera.

Como indica Papini (1979:170): “Todo nos lleva a concluir que la participación en las decisiones $(. .$.$) tiene la necesidad de una ideología anti-individualista y anti-masificante, es$ decir, de una ideología comunitaria". Esto implica una participación territorial consciente, con dimensiones de libertad, responsabilidad y de accesibilidad a la información técnica, administrativa, financiera y social producida e inclusión. Por otra parte, la planificación territorial en el municipio colombiano debe superar la disposición normativa de establecer como ordenamiento del territorio la disposición de los usos del suelo. Analiza Montes (2001:53):

Lo esencial en esta fase de transición en la planificación territorial es determinar qué grado de influencia puede tener el plan en el desarrollo efectivo de la ciudad y definir cuál es el balance justo entre el rol regulatorio del Plan de O.T. con relación al desenvolvimiento espontáneo de la ciudad. (...) la definición de las prioridades considerando las nuevas tendencias de liberalización

Citación del artículo: Urrego, G. (2017). Interdependencias y rupturas de la participación y planeación del territorio en Colombia, a partir de 1991. Revista Katharsis, N 23, enero-julio 2017, pp.236-259, Disponible en http://revistas.iue.edu.co/index.php/katharsis 
económica aplicadas a las actuaciones territoriales frente a las tradicionales necesidades sociales, especialmente en aquellos temas más sensibles como son la pobreza urbana, la vivienda social, la provisión de servicios básicos y el medio ambiente.

Es necesario que todos los actores territoriales (asociaciones sociales, culturales, gobierno local, políticos, comerciantes, campesinos, pequeños y grandes productores, entre otros) establezcan y reconozcan mecanismos de comunicación de acuerdo a características históricas, sociales y culturales locales, y esto permita armonizar los diversos lenguajes técnicos, político, administrativos; a su vez, considerar la configuración y trasformación de conflictos urbanos y rurales; relaciones de poder; regulaciones, control urbano y urbanización; dinámicas sociales, económicas, políticas de expansión urbana y ruralidad. Es decir, una producción epistémica del territorio de manera circular, que supere la visión jerárquica de las estructuras sociales y políticas de dominación local y regional a través de proyectos de desarrollo territorial. Expone Alfonso (2015:4).

Es importante aprovechar este tipo de colaboración horizontal, proyectos bilaterales entre entidades territoriales homólogas, generalmente para el intercambio de experiencias, que puedan incidir en nuevas prácticas de cooperación, muy innovadoras, para potencializar los gobiernos locales hacia nuevas fronteras de colaboración multinivel, que le puede facilitar acceso a otras posibilidades de cooperación y financiación.

Por último, en la planificación territorial en el municipio colombiano, la participación se presenta formal e informal, por una parte, la primera inicia con el reconocimiento de canales de comunicación y producción de información no convencional entre vecindades y organizaciones sociales de base (como las plazas, tiendas de barrio, grupos religiosos y artísticos). Por otra parte, la segunda participación hace referencia a los mecanismos de participación directa que establece y dispone el gobierno local municipal, a través de la Asociación de Juntas de Acción Comunal, Junta de Acción Comunal y Junta de Vivienda Comunitaria. Añade Del Cerro (2004:200):

Las trayectorias históricas de desarrollo local, las negociaciones y los conflictos entre los dominios local-regional y nacional de la acción social con el fin de extraer los beneficios del crecimiento económico, los cambios en políticas urbanas, y en general una aproximación contextualizada a los lugares donde ocurra la acción social contribuyan a esclarecer cómo y porqué se estructura y se transforma en espacio de flujos.

Las interdependencias en la planeación del territorio del municipio colombiano son, a través de, la interlocución entre actores políticos, gubernamentales, socioculturales y económicos, que permita ampliar la visión sobre el territorio. En cuanto a las rupturas entre participación y planeación del territorio en el municipio, es inacabable la reflexión y el reto del ordenamiento Citación del artículo: Urrego, G. (2017). Interdependencias y rupturas de la participación y planeación del territorio en Colombia, a partir de 1991. Revista Katharsis, N 23, enero-julio 2017, pp.236-259, Disponible en http://revistas.iue.edu.co/index.php/katharsis 
territorial, que supere la aplicación de un proceso normativo expreso en la Ley 388 de 1997, de formular un plan básico de ordenamiento territorial, sino, se considere como finalidad la implementación y evaluación del mismo a partir de la permanente discusión de las reconfiguraciones territoriales que se dan después de su formulación e implementación.

\section{Referencias}

Agudelo, L. (2010). La ciudad sostenible: Dependencia ecológica y relaciones regionales: un estudio de caso en el área metropolitana de Medellín, Colombia. Medellín: Universidad Nacional de Colombia, Facultad de Arquitectura.

Alfonso, W. (s.f.). La internacionalización de ciudades: Un nuevo desafío para el desarrollo territorial Local. Esquemas de cooperación sur/sur y de triangulación sur/sur/norte. Ekística. Universidad del Rosario. Disponible en https://drive.google.com/drive/folders/0B2-fTP_pYwnWWHRhTUluZEhBbVU

Área Metropolitana del Valle del Aburra (2010). Mecanismos de Intervención del Suelo (171204). En: Instrumentos de Gestión Urbana. Subdirección de Planificación Integral Área metropolitana del Valle de Aburra. Medellín.

Arendt, H. (2005). La condición humana. Madrid: Paidós.

Asensio, P. (2006). El Libro de la Gestión Municipal. Claves de éxito para políticos y directivos locales. Madrid: Ediciones Díaz de Santos.

Boada, M., Toledo, V. (2003). El planeta, nuestro cuerpo: La ecología, el ambientalismo y la crisis de la modernidad. $1^{\mathrm{a}}$ ed., México: Fondo de Cultura Económica.

Boisier, S. (2001). Desarrollo (Local): ¿De qué estamos hablando? Rosario: Editorial Homo Sapiens.

Botero, M. H. (2003). Desarrollo regional e internacionalización de las regiones. Documento de investigación $\mathrm{N}^{\circ}$ 3. Grupo de Estudios Regionales Universidad Del Rosario. Disponible en http://www.urosario.edu.co/cpg-ri/InvestigacionCEPI/documentos/papers/Documento_3/

Bozzano H. (2000). Territorios reales, territorios pensados, territorios posibles. Aportes para una teoría territorial del ambiente. Buenos Aires: Espacio editorial.

Cadavid, G. M. (2009). Ruralidad en contextos metropolitanos, un desafío en procesos de planeación, ordenamiento territorial y gestión. Revista Soluciones de Postgrado EIA, (4) p. 243-266. Disponible en http://eiadspace.metabiblioteca.com/bitstream/11190/662/1/RSO00046.pdf

Carrión. G.A (2008). Debilidades del nivel regional en el ordenamiento territorial colombiano. Aproximación desde la normatividad política administrativa y de usos del suelo. Grupo de Políticas y Lineamientos de Ordenamiento y Desarrollo Territorial. Ministerio de

Citación del artículo: Urrego, G. (2017). Interdependencias y rupturas de la participación y planeación del territorio en Colombia, a partir de 1991. Revista Katharsis, N 23, enero-julio 2017, pp.236-259, Disponible en http://revistas.iue.edu.co/index.php/katharsis 
Ambiente, Vivienda y Desarrollo Territorial de Colombia. Disponible en https://upcommons.upc.edu/bitstream/handle/2099/5648/9_GUSTAVO-CARRION.pdf

De Certeau, M. (2007). La invención de lo cotidiano II Habitar, cocinar. México: Universidad Iberoamericana. Traducción Alejandro Pescador, Disponible en https://monoskop.org/images/1/1c/De_Certeau_Giard_Mayol_La_invencion_de_lo_coti diano_2_Habitar_cocinar.pdf

Escuela del Hábitat - CEHAP- (2005). Conceptos básicos del plan de ordenamiento territorial. Cartilla ciudadana de preguntas y respuestas. Alcaldía de Medellín. Estrategia de Participación Ciudadana en la revisión y ajuste del POT. 1-53. Disponible en http://www.bdigital.unal.edu.co/3204/1/CartillaPot.pdf

Chaparro, M. I. (2007). Pasos firmes para la consolidación de la infraestructura colombiana de datos espaciales. Revista del Instituto Geográfico Agustín Codazzi IGAC (36). Instituto Geográfico Agustín Codazzi IGAC. 20-26 (papel)

Colombia (2015). Congreso de la República Ley 1757. Diario Oficial. 49.565

Colombia (2014). Constitución Política de Colombia, Temis

Colombia (2011). Congreso de la República Ley 1454. Diario Oficial. 48.115

Colombia (1998). Presidencia de la República Decreto 879. Diario Oficial. 43.300

Colombia (1997). Congreso de la República Ley 388. Diario Oficial. 43.09

Colombia (1994). Congreso de la República Ley 152. Diario oficial. 41.450

CorAntioquia y Grupo Territorio y Ambiente - TEAM- (2005). Determinantes Socioeconómicos y Físico-Espaciales para el Ordenamiento Territorial de la Jurisdicción de CorAntioquia. Convenio Interadministrativo Universidad de Antioquia, Corporación Académica Ambiental y Corporación Autónoma del Centro de Antioquia. Coordinador: Fernando Franco Moreno. Disponible en http://cia.corantioquia.gov.co/cgibin/koha/opac-detail.pl?biblionumber $=1510$

Del Cerro Santamaría, G. (2004). Ciudades y globalización: un enfoque teórico. Disponible en http://www.fes-sociologia.com/files/res/4/08.pdf

Departamento Nacional de Planeación (2012). Metodología para la implementación del Modelo Integrado de Planeación integrado de Planeación y Gestión. Disponible en http://www.dps.gov.co/documentos/Metodolog\%C3\%ADa\%20Implementacion\%20mod elo\%20gestion\%20_dic_2012.pdf

Escallón, J. O. (2006). Hacia una forma más eficiente de trabajar con información del territorio utilizando herramientas de captura, visibilidad y descubrimiento. Análisis geográficos. Revista del Instituto Geográfico Agustín Codazzi IGAC (30). Instituto Geográfico Agustín Codazzi IGAC. 112-120. (papel)

Espín M. J. (2009). La seguridad ciudadana y los procesos de gobernabilidad. San José: Flacso. Gallicchio, E. (2010). El desarrollo local: ¿territorializar políticas o generar políticas territoriales? Reflexiones desde la práctica. EUTOPIA, N 1, Revista de Desarrollo Económico Territorial, pp 11-23, Disponible en http://revistas.flacsoandes.edu.ec/eutopia/article/view/933

Citación del artículo: Urrego, G. (2017). Interdependencias y rupturas de la participación y planeación del territorio en Colombia, a partir de 1991. Revista Katharsis, N 23, enero-julio 2017, pp.236-259, Disponible en http://revistas.iue.edu.co/index.php/katharsis 
Gaviria, Z., Arango, M. (2007). La Dimensión de Ordenamiento Territorial en el Plan Estratégico de Antioquia. Plan Estratégico de Antioquia-PLANEA- $1^{\text {a }}$ edición.

Gómez, E., Vásquez, G., Lenti, A., Franco, L. M., Herrera, G., Aguirre, G. y Giraldo, R. (2012). Planeación participativa. Realidades y retos. Medellín: Alcaldía de Medellín y Universidad de Antioquia.

Gómez, B. y Vélez, A. (2011). Superando la técnica: planeación para construir territorio. En: Sánchez, L (edit. académica). Planeación para el desarrollo: utopía realizable (pp 36 80). Medellín: Estudio de caso programa de planeación local y presupuesto participativo, 2004-2007, Comuna 1 Popular, municipio de Medellín. Universidad de Antioquia

Gurza L., A. (1998). Estado, Sociedad y Medios. Reivindicación de lo público. México: Plaza y Valdés Editores.

Ibarra. J (2007). Reflexiones sobre el ordenamiento territorial en Colombia. Justicia Juris. Vol. 7: 37-45, Disponible en https://www.uac.edu.co/images/stories/publicaciones/revistas_cientificas/juris/volumen4-no-7/art-5.pdf

Ibarra, S. del P. (2001). Descentralización, gobernabilidad y legitimidad: una discusión politológica. Papel político. (13) 79-99. (papel)

Lefébvre H. (1974). La producción del espacio. París: Anthropos.

Lindón, A. (2006). Geografías de la vida cotidiana. En Hiernaux, D., Lindón, A (dir). Tomado del tratado de geografía humana. Barcelona: Anthropos, pp. 357-400.

Llorente, B. (2009). Desarrollo regional en Colombia. Informe GIPE al DANE. Censo 2005, Bogotá, 1 - 131. (papel)

Ministerio de Vivienda, Ciudad y Territorio. (2012). Bases conceptuales para la formulación del ordenamiento territorial departamental en el marco de la LOOT / ley 1454 de 2011 Documento preliminar, para discusión. Disponible en https://colaboracion.dnp.gov.co/CDT/Desarrollo\%20Territorial/Bases\%20conceptuales \%20para\%20la\%20formulaci\%C3\%B3n\%20del\%20ordenamiento\%20territorial\%20dep artamental\%20-\%20MVCT.pdf

Montes, P. (2001). El ordenamiento territorial como opción de políticas urbanas y regionales en América Latina y el Caribe. CEPAL. Medio Ambiente y Asentamientos Humanos. Santiago de Chile. Serie Medio Ambiente y Desarrollo (45) :1-54. Disponible en http://repositorio.cepal.org/bitstream/handle/11362/5739/1/S01111024_es.pdf

Muñoz, O y Holguín, M. (2001). El papel de los municipios colombianos en la planeación y gestión del desarrollo local: Sus fundamentos teórico- conceptuales. Tendencias, 2(2); 115-147. Disponible en http://sired.udenar.edu.co/2211/

Moreno, C.I. (2002). Relaciones entre Vivienda, ambiente y hábitat. 1-14. Disponible en http://www.bdigital.unal.edu.co/3277/1/CIM04-Relaciones.PDF

Nerys, W. (2011). IIRSA: Desafíos y oportunidades de una mega proyecto controversial. Los cambios en la Infraestructura Regional y sus Impactos Ambientales en clave de mejorar la Gobernabilidad en el Mercosur. $1^{\text {a }}$ ed. - Córdoba: Lerner Editora. 129-150.

Citación del artículo: Urrego, G. (2017). Interdependencias y rupturas de la participación y planeación del territorio en Colombia, a partir de 1991. Revista Katharsis, N 23, enero-julio 2017, pp.236-259, Disponible en http://revistas.iue.edu.co/index.php/katharsis 
Ornes, S., Chacón, R. (2009). La gestión del riesgo ambiental como eje de la planificación urbana e indicador de desarrollo local. Departamento de Planificación Urbana de la Universidad Simón Bolívar. Caracas-Venezuela. Estado de Mérida, 1-13. Disponible en http://prof.usb.ve/sornes/doc/Articulo-CISDA-SOV2009.pdf

Papini, R. (1979). La democracia de participación. En sociedad comunitaria y participación. Caracas: Editorial ateneo de Caracas.

Patiño, M. (2008). El régimen jurídico del ordenamiento ambiental y urbano en Colombia. Tesis Doctoral. Universidad de Alicante. Disponible en https://rua.ua.es/dspace/bitstream/10045/14537/1/Tesis_Patino.pdf

Peñaranda, M. (2008). Los humedales y el ordenamiento territorial en el marco del nuevo paradigma de desarrollo sostenible. Tecnología en Marcha, Vol. 21-1, enero-marzo, 228252.

Disponible

en

http://revistas.tec.ac.cr/index.php/tec_marcha/article/viewFile/1355/1257

Rengifo. J. (2012). Evolución de la planificación regional en Colombia "tendencias y perspectivas del desarrollo. XII Coloquio de Geocritica, Universidad Nacional de Colombia. Bogotá 7 al 11 de mayo. Disponible en http://www.ub.edu/geocrit/coloquio2012/actas/04-J-Rengifo.pdf

Revesz, B. (2005). Gobernabilidad democrática, descentralización y desarrollo territorial local regional. I Encuentro Macro Regional Sobre Nueva Ruralidad y Competitividad Territorial. CIPCA. Cajamarca. 1-30. Disponible en http://municipios.unq.edu.ar/modules/mislibros/archivos/gen_00889.pdf

Rojas, A., Álvarez, M, (2011). América Latina y el Caribe: Gobernabilidad Democrática. Política, Ciudadana, Exclusión, Memoria y Demografía. Buenos Aires: FLACSOAECID.

Torres, V. H. (2004). La gobernabilidad territorial y los movimientos sociales rurales en la subregión andina. Un estudio exploratorio de casos representativos del movimiento indígena en Bolivia, Perú, Colombia y Ecuador. Quito: COMUNIDEC / RIMISP Disponible en http://www.fiaes.org.sv/library/0534-005168victorhugotorresgobernabilidadrimisp.pdf

Trujillo, A. (2007). Democracia y Territorio. El ordenamiento Territorial entre el derecho y la política. Bogotá: Siglo del Hombre Editores. Academia Colombiana de Jurisprudencia.

Urrego, G. (2014). Procesos de HABITAR desde las relaciones intersubjetivas a través de los imaginarios y las acciones colectivas. Barrió Alejandro Echavarría 1950-2012. Repositorio Universidad Nacional de Colombia. Disponible en http://www.bdigital.unal.edu.co/39446/1/1017139279.2014.pdf

Vargas, H. (2007). Hacia un nuevo diseño de gobernabilidad glocal postnacional. Polis, Revista de la Universidad Bolivariana, 4 (10), Chile. 1- 17, Disponible en https://polis.revues.org/7553

Citación del artículo: Urrego, G. (2017). Interdependencias y rupturas de la participación y planeación del territorio en Colombia, a partir de 1991. Revista Katharsis, N 23, enero-julio 2017, pp.236-259, Disponible en http://revistas.iue.edu.co/index.php/katharsis 